\title{
PERANCANGAN TYPEFACE ALFABET MEMANFAATKAN AKSARA INCUNG SEBAGAI SUMBER IDE GAGASAN
}

\author{
Ria Sapitri \\ Fakultas Teknologi Informasi - Institut Teknologi Batam \\ Jl. Gajah Mada Kompleks Vitka City, Tiban Ayu - Sekupang - Batam \\ Email : sapitriria91@gmail.com
}

\begin{abstract}
ABSTRAK
Typeface merupakan "perwajahan" yang membentuk karakteristik suatu kumpulan huruf sehingga membedakannya dengan jenis huruf yang lain. Karya seni typeface dianggap mampu memberikan inspirasi baru untuk memperkenalkan salah satu kearifan lokal Kerinci yaitu aksara incung. Keindahan dan keunikan visual aksara incung mampu memberikan inspirasi baru untuk diadaptasi kedalam bentuk rancangan typeface kebaruan. Secara visual, aksara incung memiliki keindahan bentuk berupa gaya tulisan yang miring, melengkung dan patah terpancung. Bentuk dasar setiap abjad aksara incung terbentuk oleh garis yang tajam sehingga terkesan kaku dan klasik. Berdasarkan uraian di atas, maka timbul ketertarikan penulis untuk memperkenalkan atau mengakrabkan kembali aksara incung ke generasi muda sebagai identitas masyarakat Kerinci kedalam bentuk typeface kebaruan yang berbasis digital.
\end{abstract}

Kata Kunci : Typeface, Aksara, Incung Kerinci

\section{ABSTRACT}

Typeface is a "appearance" that forms the characteristics of a collection of letters so that it distinguishes it from other types of letters. Typeface artwork is considered capable of providing new inspiration to introduce one of Kerinci's local wisdoms, the incung script. Visually, incung script has the beauty of a form of writing style that is slanted, curved and broken beheaded. The basic shape of each incung alphabet is formed by sharp lines so that it seems stiff and classic. Based on the description above, the author's interest arises to introduce or familiarize the incung script back to the younger generation as the Kerinci people's identity in the form of digital-based typeface novelty.

Key Words : Typeface, Aksara, Incung Kerinci 


\section{PENDAHULUAN}

Rancangan tipografi bukan hanya font atau huruf namun ada juga istilah yang disebut dengan Typeface. Typeface adalah rancangan karakter dari sekumpulan huruf. Typeface merupakan "perwajahan" yang membentuk karakteristik suatu kumpulan huruf sehingga membedakannya dengan jenis huruf yang lain. Typeface tidak hanya mampu memberikan makna, yang mengacu pada objek atau gagasan, tetapi harus memiliki nilai fungsional dan nilai estetis sehingga mampu menyuarakan suatu citra ataupun kesan secara visual.

Dalam perkembangannya, typeface mempunyai fungsi masing-masing baik sebagai penarik perhatian (display type) dan teks yang digunakan untuk dibaca secara seksama disebut (text type) (Rustan, 2011:18). Karya seni typeface dianggap mampu memberikan inspirasi baru untuk memperkenalkan salah satu kearifan lokal Kerinci yaitu aksara incung. Aksara incung merupakan warisan budaya leluhur yang sangat berharga, bernilai sejarah, bernilai tradisi, dan bersifat lokal genius. Aksara incung yang kaya akan nilai estetika secara visual tidak mampu melekat dibenak masyarakat.

Hal ini dipengaruhi oleh beberapa faktor, seperti dinamika kehidupan modern yang terus mengikis sehingga keberadaan aksara incung ditinggalkan begitu saja. Keindahan dan keunikan visual aksara incung mampu memberikan inspirasi baru untuk diadaptasi kedalam bentuk rancangan typeface kebaruan. Secara visual, aksara incung memiliki keindahan bentuk berupa gaya tulisan yang miring, melengkung dan patah terpancung. Bentuk dasar setiap abjad aksara incung terbentuk oleh garis yang tajam sehingga terkesan kaku dan klasik. Berdasarkan uraian di atas, maka timbul ketertarikan penulis untuk memperkenalkan atau mengakrabkan kembali aksara incung ke generasi muda sebagai identitas masyarakat Kerinci kedalam bentuk typeface kebaruan yang berbasis digital.

Terciptanya karya typeface ini karena belum ditemukan karya typeface yang mengunakan karakter aksara incung sebagai ciri khas typeface budaya lokal Kerinci. Hasil rancangan typeface aksara incung diharapkan mampu memberikan pesan secara visual dan dapat digunakan oleh khalayak luas khususnya generasi muda sebagai wahana komunikasi.

Tahap selanjutnya, desain terpilih diaplikasikan ke media utama yakni soft instal data font berupa set character alphabet A-Z huruf besar (upparcase), a-z huruf kecil (lowercase), tanda baca, dan angka. Sedangkan media pendukung terdiri dari Media pendukung terdiri dari type as copywriting berupa poster dan kata-kata falsafah, marchendise seperti baju dan tas, media aplikasi sign system dan headline dalam berbagai bentuk media informasi. Rancangan ini merupakan upaya untuk memperkenalkan dan mengakrabkan aksara incung sebagai kearifan lokal Kerinci ke dalam gaya hidup generasi muda.

\section{KAJIAN SUMBER PENCIPTAAN}

1. Buku Belajar Aksara Incung Kerinci (Budhi Vrihaspathi Jauhari, Belajar Aksara Incung Kerinci, Lembaga Bina Potensia Bapeda kota Sungai Penuh Kerinci,2013). 


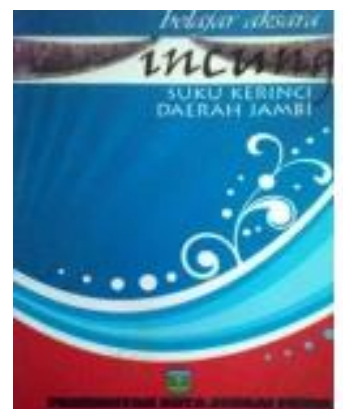

Gambar. 1 Buku "Belajar Aksara Incung Suku Kerinci” (Foto: Ria Sapitri)

Buku Belajar Aksara Incung Kerinci ini membahas tentang cara mengenal, belajar membaca, dan menulis aksara incung Kerinci. Pembahasan mengenal aksara incung Kerinci, terdiri dari pengertian aksara, aksara incung, sejarah perkembangan dan media penulisan aksara incung. Pembahasan selanjutnya, berupa belajar membaca dan menulis aksara incung yang terdiri dari penulisan dan cara pengunaan aksara incung dalam bentuk kata.

2. Karya Adien Gunarta.

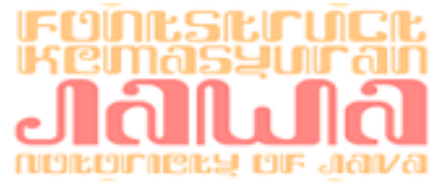

Gambar. 2 Karya Adien Gunarta, dipos 2012. (www. Iluviindonesia17.blogspot, 10-02-2017: 21.53 wib)

\section{METODE PENCIPTAAN}

Berikut beberapa metoda yang dilakukan dalam proses perancangan typeface rincung:

\section{Persiapan}

Persiapan yang dilakukan pada proses pengarapan typeface rincung adalah melakukan pengamatan langsung terhadap bentuk karakter aksara incung. Pengamatan ini dilakukan melalui proses pengumpulan data seperti, observasi, wawancara, dokumentasi dan studi pustaka. Data yang diperoleh dijadikan pedoman dalam pengarapan karya yang akan dirancang.

\section{Pengumpulan Data}

- Observasi

Melakukan kunjungan langsung ke rumah Budhi Jauhari Vrihaspathi yang merupakan budayawan ahli dalam memahami aksara incung. Observasi ini tujuan untuk menggali sumber ide dan mencari permasalahan-permasalahan yang berkaitan dengan aksara incung Kerinci. Hasil pengamatan tersebut kemudian diamati dan dianalisis secara keseluruhan untuk tahap selanjutnya.

- Wawancara

Wawancara dilakukan dengan bertanya langsung kepada bapak Budhi Jauhari Vrihaspathi selaku budayawan dan bapak Jafar selaku mantan ketua adat Suku Kerinci.

- Data Media Massa

Data media massa tersebut bisa berupa surat kabar, artikel, internet, yang berhubungan langsung dengan aksara incung, hasil karya tipografi dan proses perancangan tipografi.

- Dokumentasi

Dokumentasi dilakukan dengan memperoleh informasi mengenai aksara incung dan data visual untuk dijadikan ide perancangan typeface. Data hasil dokumentasi kemudian ditelaah untuk proses perancangan dan aplikasi media yang dianggap perlu untuk dirancang.

\section{Identifikasi Data}

Setelah data dikumpulkan, data yang diperoleh kemudian diidentifikasikan sesuai apa yang akan dirancang, baik rancangan media utama maupun media pendukung. Data yang dikumpulkan kemudian dikelompokkan dan diamati secara mendalam, data-data apa saja yang diperlukan selanjutnya dipilih dan disimpulkan mana data yang perlu dan mana data yang tidak perlu. 


\section{Analisis Data}

$5 \mathrm{~W}+1 \mathrm{H}$ :

- What apa yang akan dibuat? Rancangan yang akan dibuat yaitu perancangan typeface alfabet memanfaatkan aksara incung sebagai sumber ide gagasan.

- Where, dimana diaplikasikan/diterapkan?

diaplikasikan di daerah Kab. Kerinci dan Kota Sungai Penuh.

- When, kapan dimulai? masa sekarang dan selanjutnya.

- Who, siapa target sasaran?

Geografis:

- Masyakarat Kerinci dan sekitarnya khususnya generasi muda Demografis:

- Jenis kelamin: pria dan wanita

- Usia: 13-25 tahun (pelajar: smp, sma, sederajat dan mahasiswa/i).

- Karakter kepribadian: suka halhal baru.

- Why, mengapa rancangan typeface rincung perlu dibuat? Untuk menciptakan typeface kebaruan yang mencirikan aksara incung sebagai budaya lokal Kerinci.

- How, bagaimana merancang typeface kebaruan tersebut?

typeface yang dirancang harus mampu mengangkat citra aksara incung sebagai budaya lokal Kerinci dengan memanfaatkan karakter aksara incung kedalam typeface yang akan dirancang.

\section{PENYAJIAN DATA DAN KONSEP GARAPAN}

\section{A. Penyajian Data/ Kajian Sumber}

Terwujudnya bentuk desain typeface ini tidak terlepas dari perancang menyadari pentingnya sebuah typeface baru untuk mewakili budaya lokal Kerinci. Pentingnya typeface baru dikarenakan belum ditemukan typeface yang terinspirasi dari aksara incung sebagai typeface yang mewakili budaya lokal Kerinci. Terwujudnya perancangan ini sebagai upaya memperkenalkan dan mensosialisasikan aksara incung kepada masyarakat luas khususnya generasi muda. Konsep desain typeface ini terlahir melalui proses kreatif yang berusaha merancang sesuatu yang kreatif dan inovatif yang belum ada sebelumnya.

Oleh sebab itu, dalam proses perancangan typeface ini diperlukan riset yang mendalam bagi si perancang untuk menciptakan typeface baru yang mampu mewakili budaya lokal Kerinci yaitu aksara incung. Hal ini dilakukan agar typeface yang dirancang dapat memberikan makna dan pesan bagi masyarakat luas khususnya generasi muda di daerah Kerinci. Data dari hasil penelitian atau riset yang telah dilakukan dan terdapat beberapa yang akan dijadikan sumber perancangan diantaranya sebagai berikut:

1. Aksara Incung

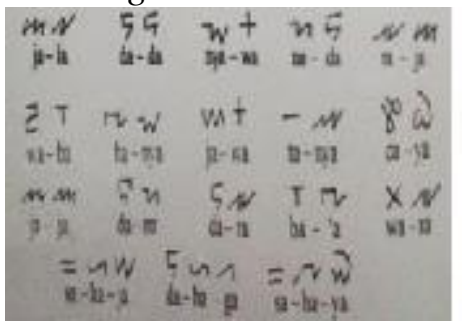

Gambar. 3 Aksara Incung (Repro: Ria Sapitri, 2017)

Aksara incung terdapat di Kabupaten Kerinci Provinsi Jambi, daerah yang memiliki aksara incung di Sumatera bagian tengah. Aksara incung Kerinci termasuk aksara tertua di Nusantara, hal ini dibuktikan dengan adanya naskah-naskah kuno berumur ratusan tahun. Naskah kuno ini berfungsi sebagai wahana untuk menulis sastra, hukum adat dan mantera-mantera 
yang ditulis pada kulit kayu, tanduk kerbau, tanduk sapi, daun lontar dan kulit kayu.

Aksara incung memiliki bentuk dan nilai-nilai keindahan, dengan kemiringan huruf sampai $45^{\circ}$, melengkung dan bentuk garis lurus patah terpancung. Tulisan Aksara incung memiliki suku kata, semuanya merupakan bunyi huruf hidup seperti tulisan Arab. Aksara pokok pada aksara incung terdiri dari 28 huruf dan terdiri dari dua atau tiga macam bentuk huruf yang berbeda-beda. Bentuk huruf tersebut dapat ditihat selperti, $G A=$ terdiri dari 2 huruf dan hurof $K A=$

terdiri dari 3 huruf yang berbeda sehingga tulisan aksara incung sulit dimengerti.

2. Set character typeface $\mathrm{A}-\mathrm{Z}$

Set character typeface A-Z merupakan wujud karya berupa alphabet A-Z baik huruf besar (upper case) dan huruf kecil (lower case). Kelengkapan alfhabet dalam sebuah character biasanya memiliki huruf besar (upper case) sebanyak 26 dan huruf kecil (lower case) dalam jumlah yang sama. Setiap jenis huruf digital memiliki jumlah character yang berbeda-beda, hal ini tergantung pada berapa banyak sang perancang huruf merancang character (Sihombing, 2003: 28-33). Contoh Set character typeface yang terdiri dari huruf besar (upper case) dan huruf kecil (lower case).

3. Type as copywriting

Type as copywriting merupakan bentuk desain berupa permainan kata-kata (copywriting) yang membawa pesan pesan tertentu. (Aryoni; 2013:88). Contoh Type as copywriting yang ditampilkan dalam bentuk poster, katakata falsafah yang diterapkan di fb dan instagram dapat dilihat sebagai berikut:

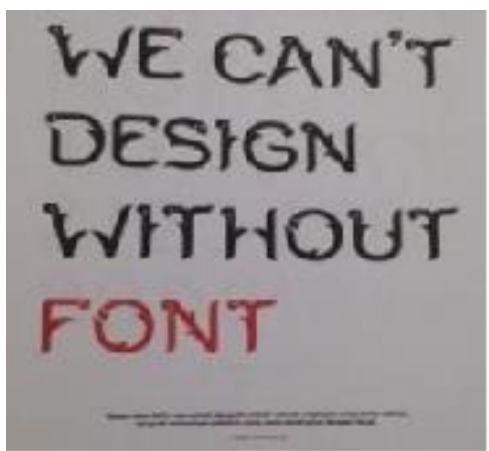

Gambar. 4 Type as copywriting dalam bentuk poster

(Sumber: Aryoni Fernanta, 2013)

Gambar di atas merupakan salah satu contoh penerapan Type as copywriting typeface rincung dalam bentuk poster. Kata yang digunakan pada penerapan type as copywriting typeface rincung adalah KOTA SAKTI ALAM KERINCI ditambah teks Ayo ke Kerinci. Pengunaan kata tersebut dikarenakan KOTA SAKTI ALAM KERINCI merupakan tagline yang sering digunakan oleh masyarakat Kerinci.

4. Type as copy writing dalam bentuk kata-kata falsafah.

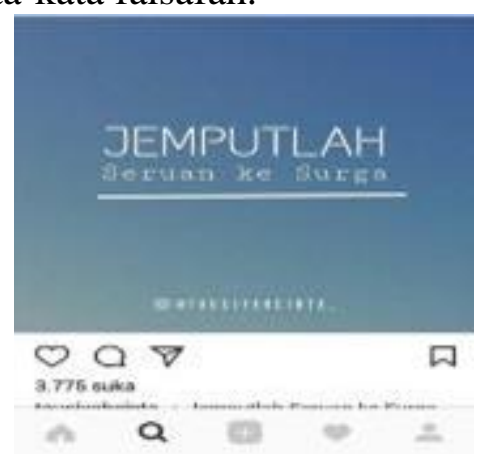

Gambar. 5 Type as copywriting Dalam

Bentuk Kata-Kata Falsafah

(Repro: Ria Safitri)

Type as copywriting dalam bentuk kata-kata falsafah di atas merupakan contoh yang dijadikan salah satu media pendukung dalam prosee perancangan nantinya. Katakata falsafah yang akan digunakan pada penerapan type as copywriting berupa sahalun suhak sataleoh bdea dan saiyo sakato, sahalun samudek. Selanjutnya, 
kata-kata falsafah tersebut diaplikasikan ke media sosial berupa instagram dan facebook dengan tujuan mensosialisasikan typeface rincung ke generasi muda.

\section{B. Konsep Garapan}

Konsep karya akan diwujudkan pada karya typefcae ini berpijak pada fenomena aksara incung itu sendiri. Aksara incung yang menjadi ikon budaya masyarakat Kerinci sudah semestinya dieksplorasi ke dunia global. Keindahan dan keunikan karakter aksara incung seperti miring, kaku, tajam, melengkung dan terpenggal menjadi ide dalam melahirkan karya typeface yang akan dirancang. Rancangan typeface ini tercipta dikarenakan belum ditemukan typeface yang mewakili aksara incung sebagai budaya lokal Kerinci. Rancangan typeface ini diharapkan mampu menghasilkan typeface baru berupa alfhabet A-Z dengan memanfaatkan karakter aksara incung sebagai ide perancangan.

Acuan dasar bentuk anatomi huruf A-Z mempertimbangkan bentuk anatomi hurufnya yang sederhana dan terkesan kaku. Karakteristik aksara incung tersebut diolah sehingga setiap huruf memiliki karakter aksara incung. Tahap selanjutnya, proses pengolahan bentuk dilakukan melalui proses disformasi dan eksplorasi. Proses disformasi merupakan pengambaran bentuk yang menekan pada interpretasi karakter, dengan cara mengubah bentuk objek dengan cara mengambarkan objek tersebut untuk mewakili atau pengambilan unsur tertentu yang mewakili karakter hasil interpretasi yang bersifat hakiki (Dharsono, 2007:72).

Desain typeface terpilih diaplikasikan pada media utama berupa 1). Uploud softdata font pada software aplikasi, typeface rincung yang sudah berupa softdata font di install pada software aplikasi desain pada operational system komputer seperti microsoft word, coreldraw, photoshop. 2). Set characters alpabet $\mathrm{A}-\mathrm{Z}$ hasil rancangan typeface rincung. yang dibuat dalam bentuk 2 dimensi dan 3 dimensi. 3).Type as copywriting, typeface rincung ditampilkan dalam bentuk poster, sign system, kata-kata falsafah yang diterapkan $\mathrm{di} \mathrm{fb}$ dan instagram. 4). Sebagai headline pada media informasi, typeface rincung ditampilkan dalam headline media informasi seperti spanduk dan baliho. 5). Aplikasi pada media marchendise seperti baju dan tas. Rancangan ini diharapkan mampu memperkenalkan dan mensosialisasikan aksara incung sebagai hasil budaya ke dalam kehidupan generasi muda.

Proses disformasi dilakukan pada penyederhanaan bentuk yaitu mengubah bentuk objek dengan cara mengabungkan karakter aksara incung seperti miring, melengkung dan patah terpenggal kedalam typeface yang akan dirancang.

\section{BENTUK KARYA SENI}

\section{A. Proses Penciptaan}

Proses perwujudan bentuk typeface yang akan dirancang sampai diaplikasikan kedalam media desain komunikasi visual dilakukan melalui beberapa tahap sebagai berikut dan nilai-nilai keindahan lainnya yang terdapat aksara incung tersebut. Bentuk dan karakteristik aksara incung inilah yang nanti akan dimanfaatkan kedalam perancangan typeface yang akan dirancang. Contoh proses elaborasi dapat dilihat sebagai berikut:

\section{Elaborasi}

Proses elaborasi dilakukan dengan menganalisa secara mendalam karakter aksara incung seperti bentuk, anatomi huruf, ketebalan huruf, gaya huruf, ukuran huruf, 


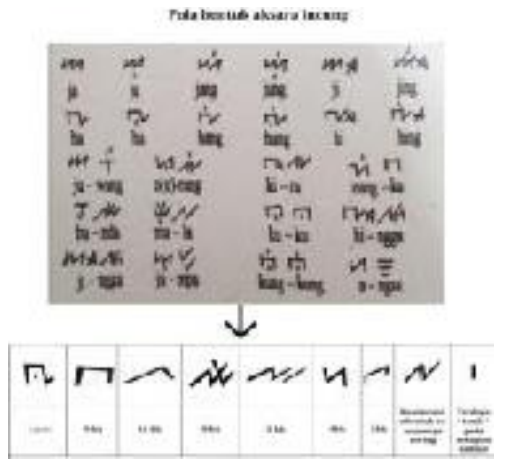

\section{Penyaringan Ide}

Dilakukan dengan pembuatan sketsa sebagai bentuk eksperimen awal dengan tujuan agar terciptanya pola dasar atau pola bentuk awal typeface yang akan dirancang.
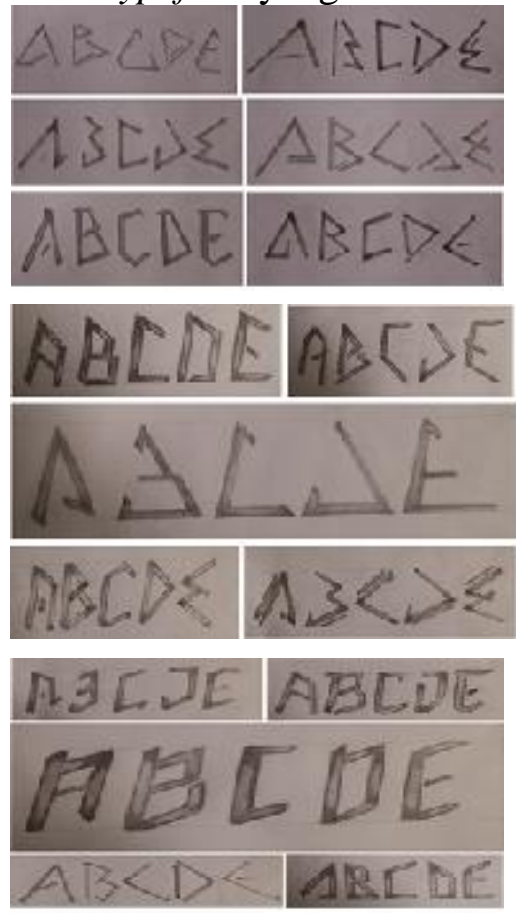

\section{Proses Transfer}

Hasil sketsa rancangan terpilih kemudian di scaning (pemindaian) dan dipindahan kedalam software grafis (adobe ilusrasi cs3). Hal ini dilakukan untuk memudahkan si perancang dalam prose pengeditan gambar yang di inginkan. Selain itu, hal ini juga bertujuan agar hasil akhir rancangan typeface lebih menarik dan rapi. Proses transfer gambar dapat dilihat sebagai berikut.

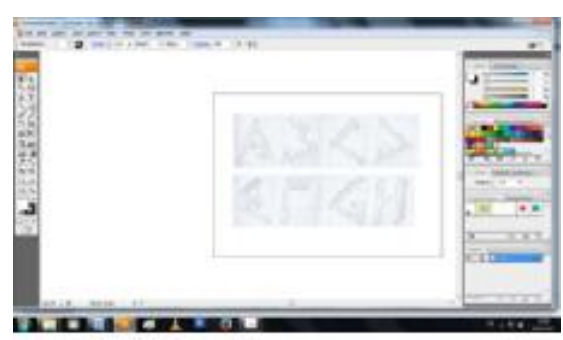

Gambar. 6 Transfer Gambar (Sumber: Ria Sapitri)

\section{Penyempurnaan Bentuk}

Proses penyempurnaan bentuk dilakukan melalui 2 cara, yaitu proses disformasi dan eksplorasi. Proses disformasi dilakukan pada penyederhanaan bentuk dengan mengambil hanya sebagian karakter aksara incung untuk diaplikasikan kedalam rancangan typeface. Selanjutnya, melakukan pengabungan antara karakter aksara incung seperti miring, melengkung dan patah terpancung dengan huruf latin. Sementara proses eksplorasi dilakukan melalui stilisasi (pengayaan) visual typeface yang diterapkan keseluruh alfabet A-Z sehingga menghasilkan bentuk typeface yang sederhana dan tidak bersifat dekoratif. Proses disformasi melalui penyempurnaan bentuk dapat dilihat sebagai berikut:

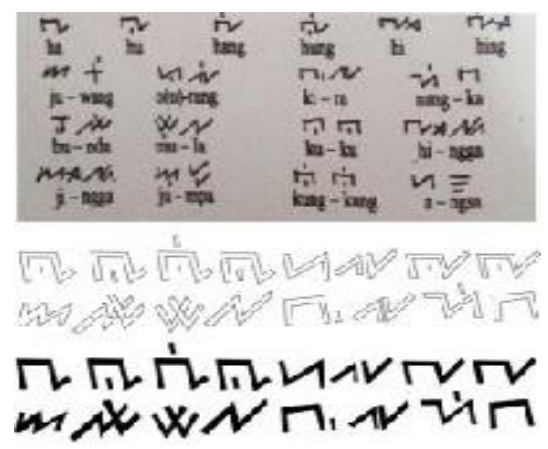

Gambar. 7 Proses Disformasi Sebagai Bentuk Pola Dasar (Sumber: Ria Sapitri) 


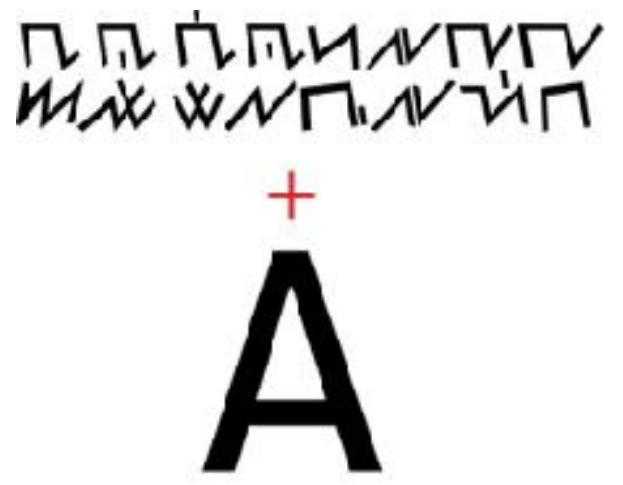

Gambar. 8 Transformasi Pada Fisik Huruf Latin Sebagai Acuan (Sumber: Ria Sapitri)

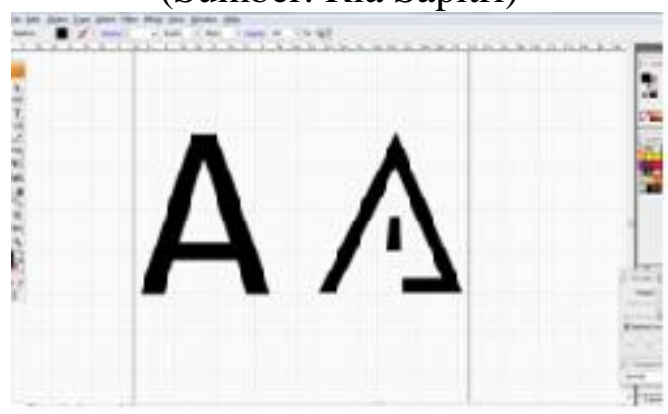

Proses penyempurnaan bentuk selanjutnya dilakukan melalui proses eksplorasi berupa stilisasi (pengayaan) visual typeface yang diterapkan keseluruh alfabet A-Z sehingga menghasilkan bentuk typeface yang sederhana dan tidak bersifat dekoratif. proses eksplorasi dapat dilihat sebagai berikut.
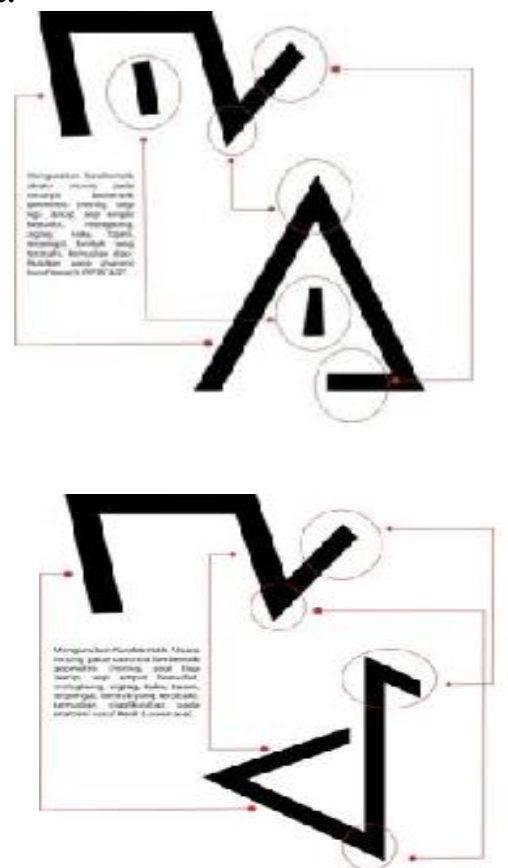

\section{Altenatif Desain}

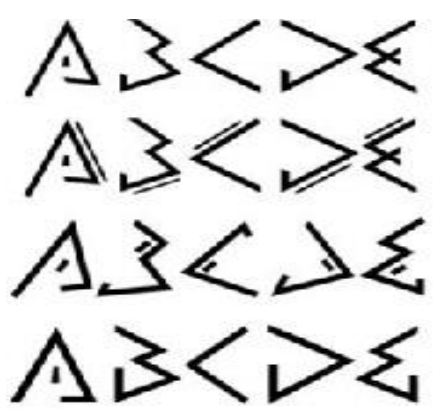

Alternatif bentuk di atas merupakan hasil transformasi objek melalui proses disformasi dan ekplorasi. Alternatif bentuk desain tersebut diambil dari 5 buah alternatif sketsa desain terpilih yang telah diproses dalam bentuk digital. 5 buah alternatif desain tersebut kemudian dikembangkan sampai terbentuk pola fisik huruf A-Z. Contoh desain alternatif dapat dilihat sebagai berikut.

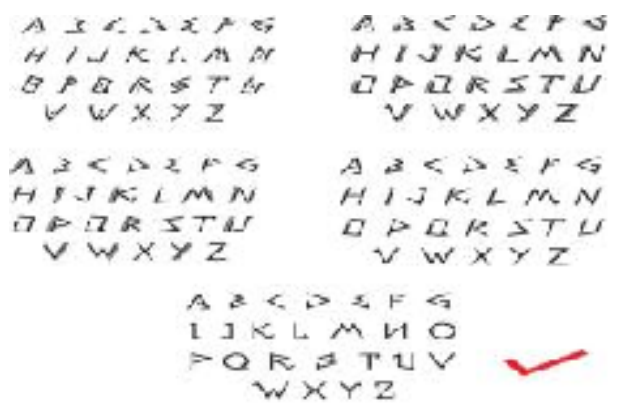

\section{Proses Editing/Finising}

Proses editing/finising dilakukan dengan cara mentransfer ulang hasil fisik huruf A-Z kedalam software editing berupa font creator. Proses ini dilakukan dengan cara mengukur kerning (jarak antar huruf) dan menentukan posisi capeline, baseline, meanline, $\quad x$-Height, Assender dan Descender. Tahap selanjutnya, typeface rincung yang telah disetting sedemikian rupa dapat di install sehingga berbentuk huruf digital. Proses editinglfinising dapat dilihat sebagai berikut: 


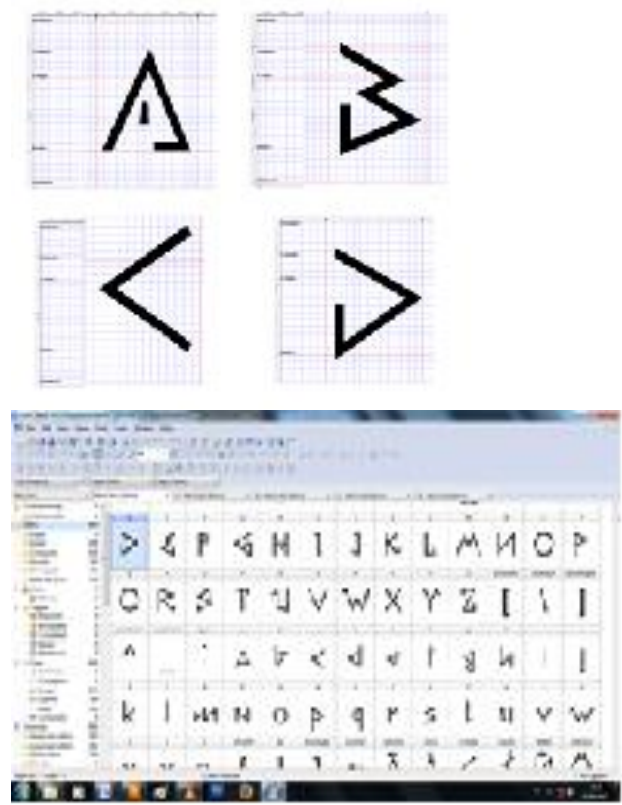

\section{Studi Kemiripan Bentuk antara Typeface Rincung dengan Aksara Incung.}

Studi kemiripan bentuk antara typeface rincung dengan aksara incung dilakukan agar hasil desain typeface rincung memiliki kesamaan bentuk dengan aksara incung itu sendiri. Menguji kemiripan ini dilakukan sebagai bentuk orisinalitas karya, sehingga karya typeface rincung murni hasil karya si perancang. Studi kemiripan bentuk antara typeface rincung dengan aksara incung dapat dilihat sebagai berikut:

\section{$K<R I N<1 \quad K \sum R l W K 1$

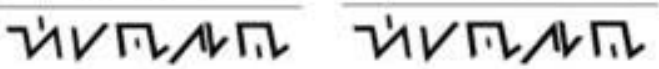

\section{$K \leqslant \mathbb{R} I N<I \quad K \leqslant R I A K I$

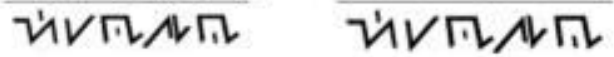

\author{
SUKSAI PEWUH SUNGAI PENIH \\ IUNA-ZHNN= IUNA-VINN= \\ SUNKGAl ASNLH SUNGAI PENUH \\ RUNA- ИIN $=$ IUNA- HINN= \\ $\$ \& A B A] P\{A G H$ \\ กИNA - VITN=
}

\section{Studi Hitam Putih

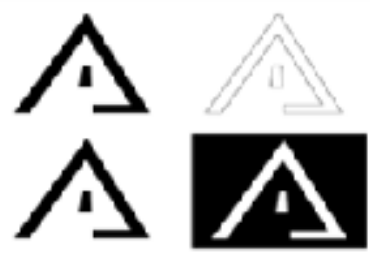

\section{B. Bentuk Karya}

1. Instal Soft Data Font

Desain typeface rincung terpilih diaplikasian melalui proses instal soft data font pada system komputer seperti microsoft Word, Photoshop, corel drow, dan adobe ilustrator. Proses instal soft data font yang telah aktif bisa digunakan sebagai salah satu alternatif piliham huruf untuk kebutuhan desain grafis. Contoh Desain typeface rincung yang sudah aktif dapat dilihat sebagai berikut: 


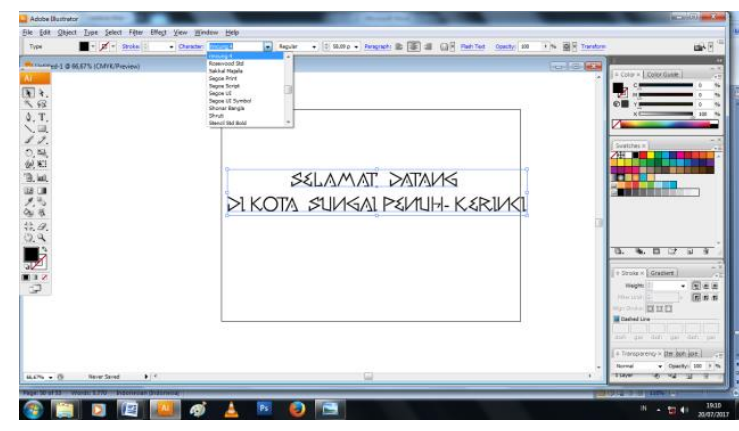

Gambar. 9 Typeface Rincung pada Software Adobe Ilustrator (Sumber: Ria Sapitri)

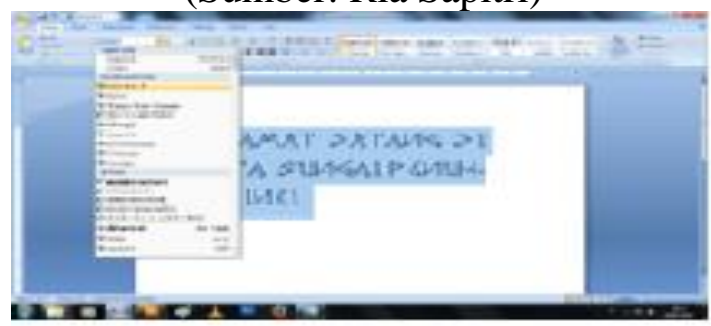

Gambar. 10 Typeface Rincung pada Software Microsoft Word (Sumber: Ria Sapitri)

\section{Set characters Alphabet A-Z}

Desain typeface rincung terpilih kemudian dibuat dalam bentuk set characters yang terdiri dari huruf besar, huruf kecil, angka dan tana baca. Masing-masing huruf harus lengkap berupa alphabet $A-Z$ baik huruf besar, huruf kecil, angka dan tanda baca. Desain typeface rincung terpilih berupa alphabet A-Z disusun sedemikian rupa sehingga dapat dibaca dan di pahami. Contoh set characters alphabet A-Z dapat dilihat ssebagai berikut:

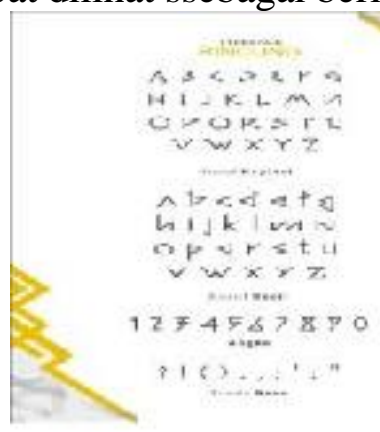

\section{Type as copywriting}

Type as copywriting merupakan bentuk permainan kata-kata yang diterapkan pada media pengaplikasian typeface rincung. Type as copywriting yang diterapkan adalah typeface rincung terpilih yang terdiri dari huruf besar (upparcase), huruf kecil (lowercase), angka dan tanda baca. Typeface rincung ditampilkan dalam bentuk poster, kata-kata falsafah yang di upload di fb dan instagram. Contoh penerapan type ascopywriting typeface rincung dapat dilihat sebagai berikut:

a. Type As Copywriting Dalam Bentuk poster

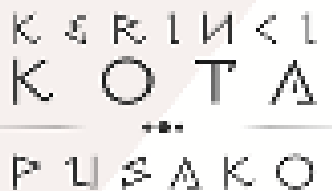

Hehe visterl

b. Type As Copywriting Dalam Bentuk Kata-Kata Falsafah.I

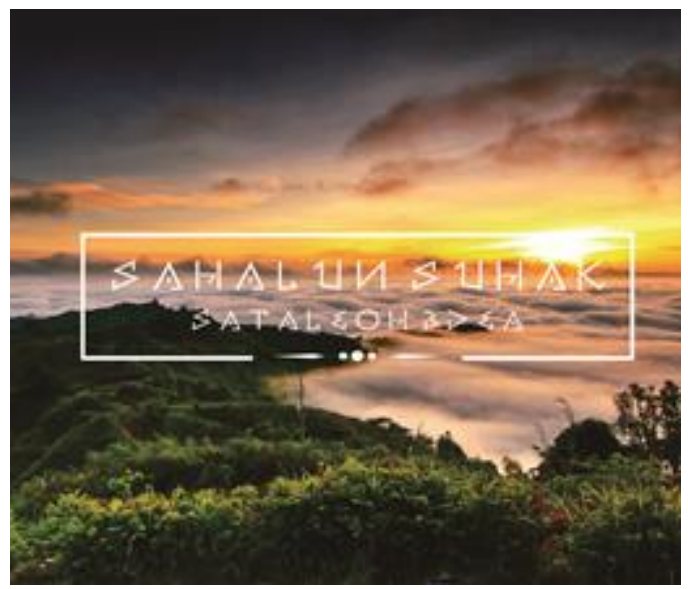

c. Type As Copywriting Dalam Bentuk Kata-Kata Falsafah yang Diterapkan pada Instagram. 


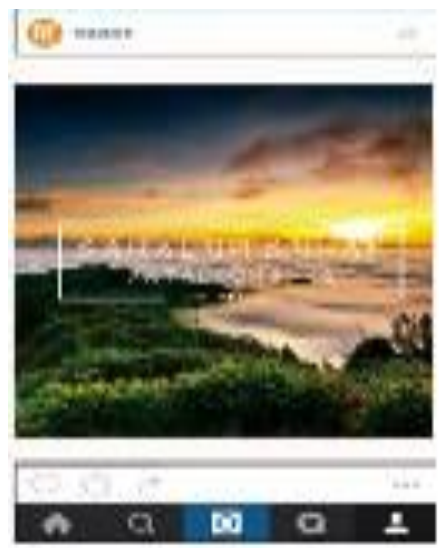

d. Aplikasi Typeface Rincung pada Media Marchendise Seperti Baju Dan Tas.
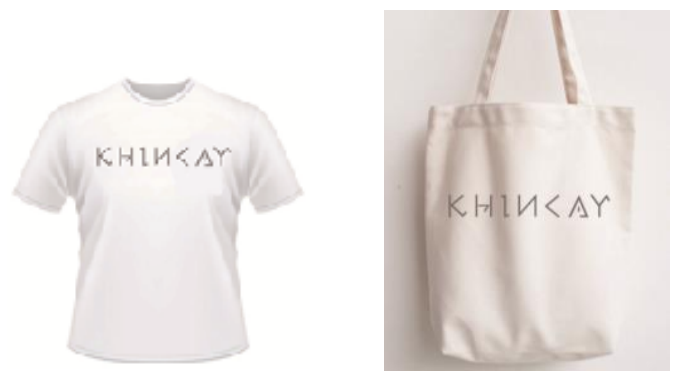

e. Aplikasi Typeface Rincung pada Sygn System

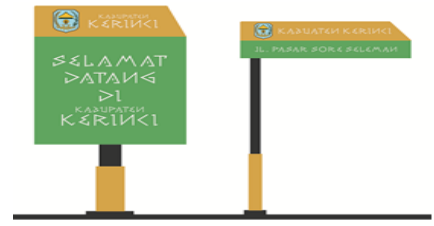

\section{Analisis Karya}

1. Deskripsi Karya

Secara visual, karya yang dirancang mengunakan konsep reinterpretasi dengan memanfaatkan karakter aksara incung sebagai ide perancangan. Bentuk-bentuk yang ditransformasikan ke fisik huruf typeface rincung ialah karakter aksara incung seperti huruf bersifat geometris, miring, kaku, tajam, melengkung, dan terpenggal. karakter aksara incung yang ditampilkan pada karya dilakukan melalui proses perwujudan yakni proses disformasi dan ekplorasi.

Proses disformasi dilakukan pada penyederhanaan bentuk dengan memanfaatkan sebagian karakter aksara incung, kemudian digabungkan kedalam huruf latin A-Z. Sementara proses eksplorasi dilakukan melalui stilisasi (pengayaan) visual typeface yang diterapkan keseluruh alfabet A-Z. Proses stilisasi (pengayaan) dimulai dari huruf A sampai ke huruf $\mathrm{Z}$ sehingga setiap fisik huruf mampu mewakili karakter aksara incung itu sendiri.

Rancangan typeface rincung tidak bersifat dekoratif, dikarenakan pada setiap fisik huruf tidak terdapat ornament maupun motif motif. Bentuk typeface rincung pada umunya bersifat geometris, yang mana pada setiap fisik huruf menampilkan bentuk segitiga dan segiempat bersudut. Kesan kaku, tajam dan klasik dapat dilihat pada setiap fisik huruf rincung baik huruf besar (uppercase), huruf kecil (lowercase), angka dan tanda baca.

Rancangan typeface rincung tidak terlalu rumit hal ini dikarenakan pertimbangan dari faktor keterbacaan (legibility) serta kejelasan (readibility). Faktor keterbacaan (legibility) serta kejelasan (readibility) dapat dilihat pada setiap pengaplikasiian huruf seperti poster, baju, tas, kata falsafah dan sign sytem. Selain itu, keunikan dari typeface ini yaitu typeface rincung mampu merepresentasikan karakter aksara incung.

\section{SIMPULAN}

Konsep reinterpretasi berupa proses disformasi dan eksplorasi menjadi bagian penting dalam melahirkan karya typeface rincung ini. Hal ini dikarenakan perancang ingin menciptakan sebuah karya kebaruan typeface yang mampu mewakili budaya lokal kerinci yakni aksara incung.

Perancangan typeface alphabet dengan memanfaatkan aksara incung sebagai ide perancangan merupakan judul dari laporan 
karya tugas akhir ini. Wujud karya yang diciptakan oleh perancang lebih menekan pada kesan klasik dan tradisional dari karakter aksara incung itu sendiri. Karakter aksara incung seperti miring, tajam, kaku, berbentuk segitiga dan segi empat bersudut akan dihadirkan kedalam karya typeface rincung itu sendiri. Hasil final desain karya typeface rincung ini diaplikasikan pada media utama yakni instal softdata font pada software komputer.

Hasil instal softdata font berupa set character alphabet A-Z akan diaplikasikan ke media pendukung seperti, Type as copywriting berupa poster dan kata-kata falsafah, media marchendise seperti baju dan tas, dan aplikasi ke media sign system.

Perancangan typeface rincung ini akan diciptakan dalam bentuk 2D (print out)dan 3D dengan ukuran karya yang berbedabeda. Hal ini harus disesuaikan dengan setiap kebutuhan dan keperluan yang diinginkan. Terciptanya karya ini bertujuan untuk melahirkan karya typeface baru yang mampu mewakili budaya lokal Kerinci yakni aksara incung.

\section{UCAPAN TERIMAKSIH}

Syukur Alhamdulillah penulis panjatkan atas kehadiran Allah SWT, Yang memiliki keistimewaan dan pemberian segala kenikmatan besar, baik nikmat iman, kesehatan dan kekuaran didalam melakukan penelitian ini. Selawat dan salam senantiasa tercurahkan kepada Sayyidina Muhammada SAW. Pada kesempatan ini penulis menyampaikan rasa terimakasih kepada

\section{DAFTAR PUSTAKA}
Hasti Lumenta, Natalia. Typeface "Garuda Batik" sebagai Duta Budaya Indonesia. Yogyakarta: ASRD Modern School of Design

Kusrianto, Adi. 2004. Tipografi Komputer untuk Desainer Grafis. Andi: Yogyakarta.
Lembaga Bina Potensia dan Bappeda Kota Sungai Penuh. 2013. Belajar Aksara Incung Suku Kerinci Daerah Jambi. Sungai Penuh: Pemerintah Kota Sungai Penuh.

Mubarat, Husni. 2010. Ekspresi Aksara Incung Dalam Penciptaan Seni Kriya. Padangpanjang: Program Studi Pascasarjana.

Pusat Bahasa, 2008. Kamus Besar Bahasa Indonesia Edisi Empat. Gramedia Pustaka Utama: Jakarta.

Patriansyah, Mukhsin. 2013. Katak Sebagai Ekspresi Simbolik. Padangpanjang: Program Studi Pascasarjana.

Ratna, Nyoman Khuta. 2007. Estetika, Bandung: Rekayasa Sains.

Rustan, Surianto.2011. Huruffontipografi. Jakarta: PT. Gramedia.

Sihombing, Danton. 2003. Tipografi dalam Desain Grafis. PT Gramedia Pustaka Utama: Jakarta.

Sony Kartika, Dharsono. 2007. Estetika. Bandung: Rekayasa Sains.

Tinarbuko, Sumbo. 2018. Semiotika Komunikasi Visual. Yogyakarta: Jalasutra.

Vrihaspathi Jauhari Budhi, Mardizal Joni, dkk. 2013. Mengenal Aksara Incung Suku Kerinci Daerah Jambi. Sungai Penuh dan Kabupaten Kerinci Provinsi Jambi: Lembaga Bina Potensia Aditya Mahatva Yodha Kota. 